\title{
Capsular-type prediction by phylogenetic tree of glycosyltransferase gene polymorphism in Streptococcus pneumoniae
}

This article was published in the following Dove Press journal:

Open Access Bioinformatics

10 March 201I

Number of times this article has been viewed

\author{
Yuka Tomita ${ }^{1,2}$ \\ Akira Okamoto 2 \\ Keiko Yamada ${ }^{2}$ \\ Testuya Yagi ${ }^{3}$ \\ Yoshinori Hasegawa ${ }^{4}$ \\ Michio Ohta ${ }^{2}$ \\ 'Department of Infectious Disease, \\ Nagoya University Hospital, \\ 2Department of Bacteriology, \\ Nagoya University Graduate School \\ of Medicine, ${ }^{3}$ Center of National \\ University Hospital for Infection \\ Control, Nagoya University Hospital, \\ ${ }^{4}$ Department of Respiratory Medicine, \\ Nagoya University Graduate School of \\ Medicine, Nagoya, Japan
}

\begin{abstract}
Streptococcus pneumoniae can cause severe infections among children and the elderly. Molecular capsule typing is being investigated extensively as a replacement of conventional serotyping using antisera. We focused on the glycosyltransferase (GT) genes in the capsular polysaccharide synthesis (cps) gene cluster of $S$. pneumoniae for classification of capsular types. The Sanger Institute provided sequences of the cps loci of 90 serotypes of $S$. pneumoniae. Each cps locus contained 1-6 putative GT genes per strain, for a total of 352 GT genes. Phylogenetic analysis of GT gene polymorphisms distinguished 90 serotypes into 64 phylogenetic groups. However, the sequence data contained only one sample from each serotype. Therefore, we selected six clinical isolates belonging to serogroup 6 and seven clinical isolates belonging to serotype $19 \mathrm{~F}$ by antisera and sequenced GT genes. From phylogenetic analysis, these sequences were very similar to those of the Sanger Institute, and we can use GT genes as serotype-specific genes.
\end{abstract}

Keywords: Streptococcus pneumoniae, phylogenetic tree, glycosyltransferase gene

\section{Introduction}

Streptococcus pneumoniae is a common Gram-positive pathogen that colonizes the upper respiratory tract. The bacterium can cause severe infections, such as otitis media and sinusitis, and more life-threatening diseases, such as pneumonia, bacteremia, and meningitis if it gains access to the lower respiratory tract or the bloodstream. ${ }^{1}$ S. pneumoniae can be divided into $>90$ serotypes based on differences in the composition of the capsular polysaccharides. ${ }^{2,3}$ However, only seven serotypes (4, 6B, $9 \mathrm{~V}, 14,18 \mathrm{C}, 19 \mathrm{~F}$, and $23 \mathrm{~F}$ ) are responsible for $65 \%$ of all cases of pneumococcal disease $e^{4}$ and 23 serotypes for $90 \%$ of cases. ${ }^{5}$ The emergence of antibiotic resistance and the spread of resistant strains have increased the importance of vaccines as a primary prevention. The serotypes of $S$. pneumoniae most commonly isolated from patients with invasive pneumococcal disease vary in different age groups and geographic locations. ${ }^{6}$ Therefore, continued surveillance is critical in order to monitor vaccine efficacy and changes in incidence and distribution of colonizing and invasive serotypes. Any increase in disease caused by previously uncommon nonvaccine serotypes could necessitate a change in vaccine composition. Various methods are currently used to identify pneumococcal serogroup and serotype using large panels of expensive antisera. These methods include the capsular swelling (Quellung) reaction, latex agglutination, and coagglutination. ${ }^{7-9}$ Cross-reactions between serotypes and discrepancies between methods can occur and some strains are nonserotypable., ${ }^{7,11}$ 
Molecular typing has the potential to improve discrimination and provide additional information.

With the exception of serotypes 3 and 37, which are produced by the synthase pathway, pneumococcal capsular polysaccharides (CPSs) are generally synthesized by the Wzx/Wzy-dependent pathway. ${ }^{12}$ The genes for the latter pathway are located at the same chromosomal locus (cps), between $\operatorname{dex} B$ and aliA. ${ }^{13}$ The DNA sequences of the 90 pneumococcal cps loci have been determined by the Sanger Institute. ${ }^{12}$ There are four conserved genes (wzg, wzh, wzd, and $w z e$ ) at the $5^{\prime}$ end of all S. pneumoniae cps loci that use the Wzy pathway. The cps loci also include genes whose products are involved in the biosynthesis of nonhouskeeping components (cps-specific biosynthesis pathway genes), initiation of capsule biosynthesis (initial sugar transferase genes), and transfer of sugar moieties and their assembly in the repeat unit (glycosyltransferase [GT], acetyltransferase, sugar phosphate transferase, and pyruvyltransferase genes). ${ }^{14}$ GT proteins catalyze the formation of glycosidic bonds between the lipid-linked glycan precursor (acceptor) and a nucleotide-activated sugar (donor). Therefore, GT proteins determine the sequence of components in the repeating polysaccharide units that comprise pneumococcal capsules.

The GT genes in the cps loci were examined to determine their utility in using phylogenetic analysis to classify the serotypes of $S$. pneumoniae.

\section{Materials and methods}

\section{Phylogenetic analysis}

The nucleotide sequences of the GT genes in S. pneumoniae cps loci were retrieved from the database of the Sanger Institute (accession numbers CR931632-CR931722; see http:// www.sanger.ac.uk/Projects/S_pneumoniae/CPS/). A phylogenetic tree was made by the neighbor-joining method using program Clustal_X ${ }^{15}$ and visualized with Njplot. ${ }^{16}$

\section{Clinical isolates and growth conditions}

Clinical specimens were selected from isolates submitted to hospital laboratories in Japan from 1998 to 2007. The isolates were frozen at $-80^{\circ} \mathrm{C}$ in brain-heart infusion broth (Eiken,
Tokyo, Japan) supplemented with $0.3 \%$ yeast extract (Becton Dickinson, Boston, MA) (BHI-Y) with 80\% glycerol. Frozen isolates were subcultured on blood agar medium containing sheep erythrocytes (Denka Seiken, Tokyo, Japan) or grown in BHI-Y for $24 \mathrm{~h}$ at $37^{\circ} \mathrm{C}$ in $5 \% \mathrm{CO}_{2}$.

The isolates were identified as $S$. pneumoniae by colony morphology, alpha hemolysis, and optochin susceptibility in the clinical laboratories that isolated each strain. Six pneumococcal strains representing serogroup 6 (D11, D12, D13, D14, D19, and D25) and seven representing serotype 19F (D5, D15, D20, D28, D33, D50, and D53) were chosen for study.

Serotyping was performed by a slide agglutination test (Denka Seiken, Tokyo, Japan) or by the Quellung reaction (Statens Serum Institut, Copenhagen, Denmark).

\section{Genomic DNA extraction}

S. pneumoniae isolates were grown in BHI-Y at $37^{\circ} \mathrm{C}$ in the presence of $5 \% \mathrm{CO}_{2}$ for 24 hours. Following sedimentation, the cells were resuspended in $450 \mu \mathrm{L}$ of $50 \mathrm{mM}$ EDTA and $12 \mu \mathrm{L}$ of lysozyme $(100 \mathrm{mg} / \mathrm{mL})$. The cells were incubated for 1 hour at $37^{\circ} \mathrm{C}$ before genomic DNA was extracted using a Wizard Genomic DNA Purification Kit (Promega, Madison, WI).

\section{Gene amplification, sequencing, and alignment}

The primers were designed to target two GT genes: wciP of serotype 6B and wch $Q$ of serotype 19F. Sequences of the targeted genes were retrieved from the website of the Sanger Institute. All primers were synthesized by Invitrogen (Tokyo, Japan). The primer designations, sequences, product sizes, and numbered base positions are shown in Table 1 .

Thermal cycling was performed in the GeneAmp PCR System 9700 (Applied Biosystems) under the following conditions: $94^{\circ} \mathrm{C}$ for 5 minutes followed by 30 amplification cycles of $94^{\circ} \mathrm{C}$ for 30 seconds, $55^{\circ} \mathrm{C}$ for 30 seconds, and $72^{\circ} \mathrm{C}$ for 1 minute, then a final extension at $72^{\circ} \mathrm{C}$ for 7 minutes. The PCR amplicons were extracted after agarose

Table I Oligonucleotide primers used in this study

\begin{tabular}{llllll}
\hline Serotype & GT gene & Primer name & Primer sequence $\left(\mathbf{5}^{\prime} \rightarrow \mathbf{3}^{\prime}\right)$ & Nucleotide position & Product size (bP) $^{\text {a }}$ \\
\hline 6B & wciP & 6B-wciP-F & aat act ata aaa ata ctg gc & 8021 & 1233 \\
& & 6B-wciP-R & ccc tca aat aat ata aat gt & 9253 & 1196 \\
I9F & I9F-wchQ-F & ara aag tat gat tgg aaa aa & 9752 & 1196 \\
& & I9F-wchQ-R & wtr aaa gca aar aaa tag aa & 10947 & \\
\hline
\end{tabular}

Note: aStart position of each primer are represented. 
gel electrophoresis and purified with the QIAprep Spin Miniprep Kit (250) (Qiagen, Tokyo, Japan).

The PCR products were sequenced using dye terminator cycle sequencing with the CEQ8000 DNA Analysis System (Beckman Coulter, Fullerton, CA). The corresponding amplification primers or inner primers were used as sequencing primers.

DNA sequences were aligned and edited using Sequencher software (Gene Codes, Ann Arbor, MI).
Multiple-sequence alignments were performed with the Genetyx program (Genetyx, Tokyo, Japan).

\section{Results \\ Phylogenetic analysis of the GT gene sequences}

The assignment of gene functions predicted by the Sanger Institute found 352 putative GT genes (including pseudogenes) in the cps loci of $90 \mathrm{~S}$. pneumoniae. Each

Table 2 Glycosyltransferase genes of each serotype

\begin{tabular}{|c|c|c|c|c|c|c|c|c|c|c|c|c|}
\hline \multirow{2}{*}{$\frac{\text { Serotype }}{I}$} & \multicolumn{5}{|c|}{ GT genes included in cps locus } & \multirow{2}{*}{$\begin{array}{l}\text { Serotype } \\
19 \mathrm{C}\end{array}$} & \multicolumn{6}{|c|}{ GT genes included in cps locus } \\
\hline & $w c h B$ & wchD & & & & & wchO & wchQ & wchS & wchU & & \\
\hline 2 & $w c h F$ & wchG & wchH & wchl & & 20 & $w c i B$ & whal & wcil & $w c w K$ & $w c i D$ & whaF \\
\hline 3 & wchE & & & & & 21 & $w c h F$ & $w C w A$ & $w c w K$ & $w c y T$ & $w c y U$ & \\
\hline 4 & wcij & wciK & wcil & & & $22 \mathrm{~F}$ & wchF & wCwA & $w c w V$ & whaB & & \\
\hline 5 & wcil & whac & whaD & & & $22 \mathrm{~A}$ & wchF & wCwA & $w c w V$ & whaB & & \\
\hline $6 \mathrm{~A}$ & wciN & wciP & & & & $23 \mathrm{~F}$ & $w c h F$ & wchV & wchW & & & \\
\hline $6 \mathrm{~B}$ & wciN & wciP & & & & $23 \mathrm{~A}$ & wchF & wchV & wchW & & & \\
\hline $7 F$ & wchF & $w C w A$ & $w C w F$ & $w c w G$ & $w c w H$ & $23 B$ & $w c h F$ & wchV & wchW & & & \\
\hline $7 A$ & wchF & wCWA & $w C w F$ & $w C w G$ & $w c w H$ & $24 \mathrm{~F}$ & wchF & $w C x l$ & $w C x J$ & & & \\
\hline $7 B$ & $w c h F$ & $w c w l$ & $w C w L$ & wcwK & $w c x U$ & $24 \mathrm{~A}$ & $w c h F$ & $w c x l$ & $w \subset x J$ & & & \\
\hline $7 C$ & wchF & wcwl & $w C w L$ & wcwK & $w c x U$ & $24 B$ & wchF & $w c x \mid$ & $w c x J$ & & & \\
\hline 8 & wciO & $w c i R$ & wciS & wciT & & $25 \mathrm{~F}$ & $w c y A$ & $w c y B$ & wcyC & wcyD & wcyE & \\
\hline $9 A$ & wchO & $w c j A$ & $w c j B$ & $w c j C$ & & $25 \mathrm{~A}$ & $w c y A$ & $w c y B$ & wcyc & $w c y D$ & wcyE & \\
\hline $9 \mathrm{~V}$ & wchO & $w c j A$ & $w c j B$ & $w c j C$ & & 27 & wchF & whaK & wcys & & & \\
\hline 9L & wchO & $w c j A$ & $w c j B$ & wcjC & & $28 \mathrm{~F}$ & wchF & wcil & $w c x N$ & & & \\
\hline $9 N$ & wchO & $w c j A$ & $w c j B$ & wcjC & & $28 \mathrm{~A}$ & wchF & wciU & $w c x N$ & & & \\
\hline $\mathrm{IOF}$ & $w c i B$ & wcrC & $w c r D$ & wciF & wcrH & 29 & $w c i B$ & wcrM & wcrH & & & \\
\hline $10 \mathrm{~A}$ & $w c i B$ & $w c r C$ & $w c r D$ & wciF & $w c r G$ & 31 & wciB & $w C r P$ & $w c r R$ & werW & $w c r X$ & \\
\hline $10 B$ & $w c i B$ & wcrC & $w c r D$ & wciF & wcrG & $32 \mathrm{~F}$ & $w c h F$ & wchQ & wcys & & & \\
\hline $10 C$ & wciB & wcrC & $w c r D$ & wciF & wcrH & $32 \mathrm{~A}$ & wchF & wchQ & wcys & & & \\
\hline IIF & wchK & wcyK & wcrL & & & $33 \mathrm{~F}$ & wciB & wciC & wciD & wciE & wciF & \\
\hline IIA & wchK & wcyk & wCrL & & & $33 \mathrm{~A}$ & wciB & wciC & wciD & wciE & wciF & \\
\hline IID & wchK & wcyK & wcrL & & & $33 B$ & wciN & werC & wciD & wciE & wciF & \\
\hline IIB & wchK & wcyK & wcrL & & & $33 C$ & wciN & werC & $w c r D$ & wciF & & \\
\hline IIC & wchK & wcyK & wcrL & & & $33 D$ & wciN & wcrC & wciD & wciE & wciF & \\
\hline $\mathrm{I} 2 \mathrm{~F}$ & wcil & $w C x B$ & $w c x D$ & $w c x E$ & $w c x F$ & 34 & $w c i B$ & wcrC & $w c r D$ & & & \\
\hline $12 \mathrm{~A}$ & wcil & $w c x B$ & $w c x D$ & $w c x E$ & $w C x F$ & $35 \mathrm{~F}$ & wciB & wcrC & $w c r D$ & & & \\
\hline $12 B$ & wcil & $w C x B$ & $w c x D$ & $w C x E$ & $w c x F$ & $35 \mathrm{~A}$ & $w c i B$ & wcrl & wcrk & wcrH & & \\
\hline 13 & wchK & wciF & $w c r D$ & & & $35 B$ & $w c i B$ & wcrM & wcrH & & & \\
\hline 14 & wchK & wchL & wchM & $w c h N$ & & $35 \mathrm{C}$ & $w c i B$ & wcrl & wcrk & wcrH & & \\
\hline $15 \mathrm{~F}$ & wchK & wchL & wchM & $w c h N$ & & 36 & wchO & $w c j A$ & wciF & wcrH & & \\
\hline I5A & wchK & wchL & wchM & $w c h N$ & & 37 & wciB & wciC & $w c i D$ & wciE & wciF & \\
\hline I5B & wchK & wchL & wchM & $w c h N$ & & 38 & $w c y A$ & $w c y B$ & wcyC & wcyD & wcyV & \\
\hline $15 \mathrm{C}$ & wchK & wchL & wchM & $w c h N$ & & 39 & $w c i B$ & wciE & wcrC & $w c r D$ & wciF & wcrG \\
\hline $16 \mathrm{~F}$ & $w c h F$ & wciU & $w c x N$ & & & 40 & wchF & wCwl & $w C w L$ & wcwK & $w c x U$ & \\
\hline $16 \mathrm{~A}$ & wchK & wcyK & $w c x S$ & wciB & & $4 I F$ & wciB & $w c r P$ & wcrQ & $w c r R$ & $w c r X$ & \\
\hline $17 F$ & wchF & wcip & werV & & & $4 I A$ & wciB & wcrP & wcrQ & $w c r R$ & $w c r X$ & \\
\hline I7A & $w c i B$ & $w c r P$ & wcrQ & $w c r R$ & werV & 42 & $w c i B$ & werl & wcrk & wcrH & & \\
\hline $18 \mathrm{~F}$ & wchF & wciU & wciV & wciW & & 43 & $w c i B$ & wciE & wcrC & wсуM & wcyN & wcrH \\
\hline $18 \mathrm{~A}$ & $w c h F$ & wciU & wciV & wciW & & 44 & wcil & $w C x B$ & $w c x D$ & $w c x E$ & $w c x F$ & \\
\hline $18 B$ & wchF & wciU & wciV & wciW & & 45 & wcil & $w C x B$ & wcil & $w c x S$ & & \\
\hline $18 C$ & wchF & wcil & wciV & wciW & & 46 & wcil & $w C x B$ & $w C x D$ & $w C x E$ & $w C x F$ & \\
\hline $19 \mathrm{~F}$ & wchO & wchQ & & & & $47 \mathrm{~F}$ & $w c i B$ & wcrC & wcrD & & & \\
\hline $19 \mathrm{~A}$ & wchO & wchQ & & & & $47 \mathrm{~A}$ & wciB & wcrC & wсyM & wcyN & whaM & \\
\hline $19 B$ & wchO & wchQ & wchS & & & 48 & $w c h F$ & wcys & & & & \\
\hline
\end{tabular}

Abbreviations: cps, capsular polysaccharide synthesis; GT, glycosyltransferase. 
cps contained 1 to 6 GT genes (Table 2). A phylogenetic tree was constructed to explore the sequence diversity and relatedness of the GT genes in each cps locus. The nucleotide sequences from the Sanger Institute inserted into Clustal_X produced a phylogenetic tree showing that GT genes are highly variable and are therefore suitable targets for serotype/serogroup identification (Figure 1). A comparison of the sequences of neighboring GT genes showed that some were highly similar while others shared partial similarity. For example, according to the Sanger database, two serotypes in serogroup 6 (6A and 6B) have two GT genes, wciN and wciP. The phylogenetic tree and sequence alignment showed that while the wciN nucleotide sequences of the two serotypes were almost identical, they shared only partial similarity with wciN from serotype 33D (Figure 2A). Therefore, serogroup 6 and serotype 33D were distinguishable based on the nucleotide sequence of wciN. Another GT gene in serogroup 6, wciP, shared a minor similarity with $w c i P$ in serotype $17 \mathrm{~F}$, therefore, the nucleotide sequence of $w c i P$ could be used to separate serogroup 6 and serotype 17F (Figure 2B). Further analysis of GT gene sequences revealed that $90 \mathrm{~S}$. pneumoniae serotypes

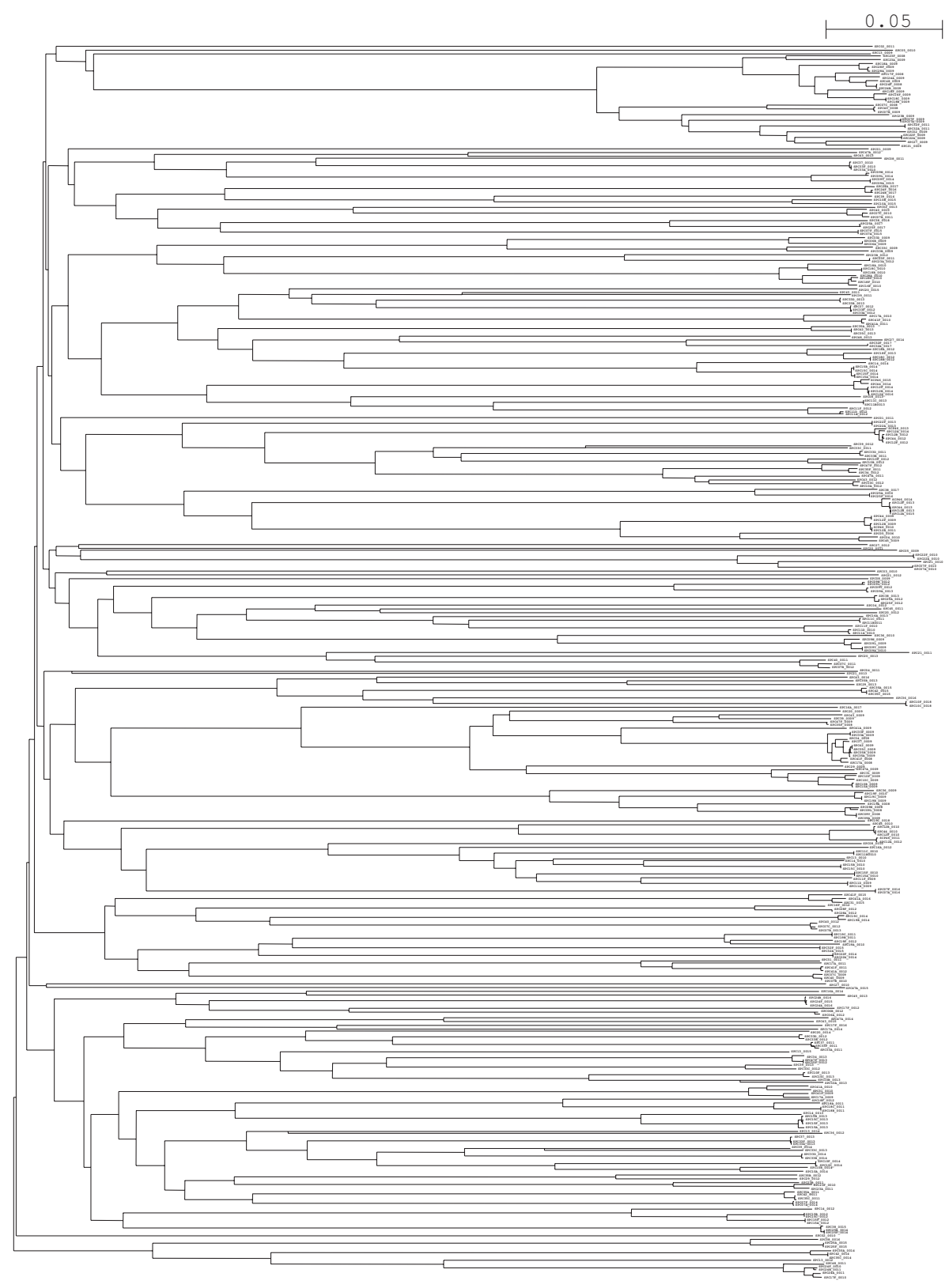

Figure I Phylogenetic tree generated from glycosyltransferase gene sequences in the capsular polysaccharide synthesis locus of 90 S. pneumoniae serotypes from the Sanger Institute database. All nucleotide sites were used to construct the tree using the neighbor-joining method. The sequence names are given as SPC-serotype-Sanger Institute database gene number. 

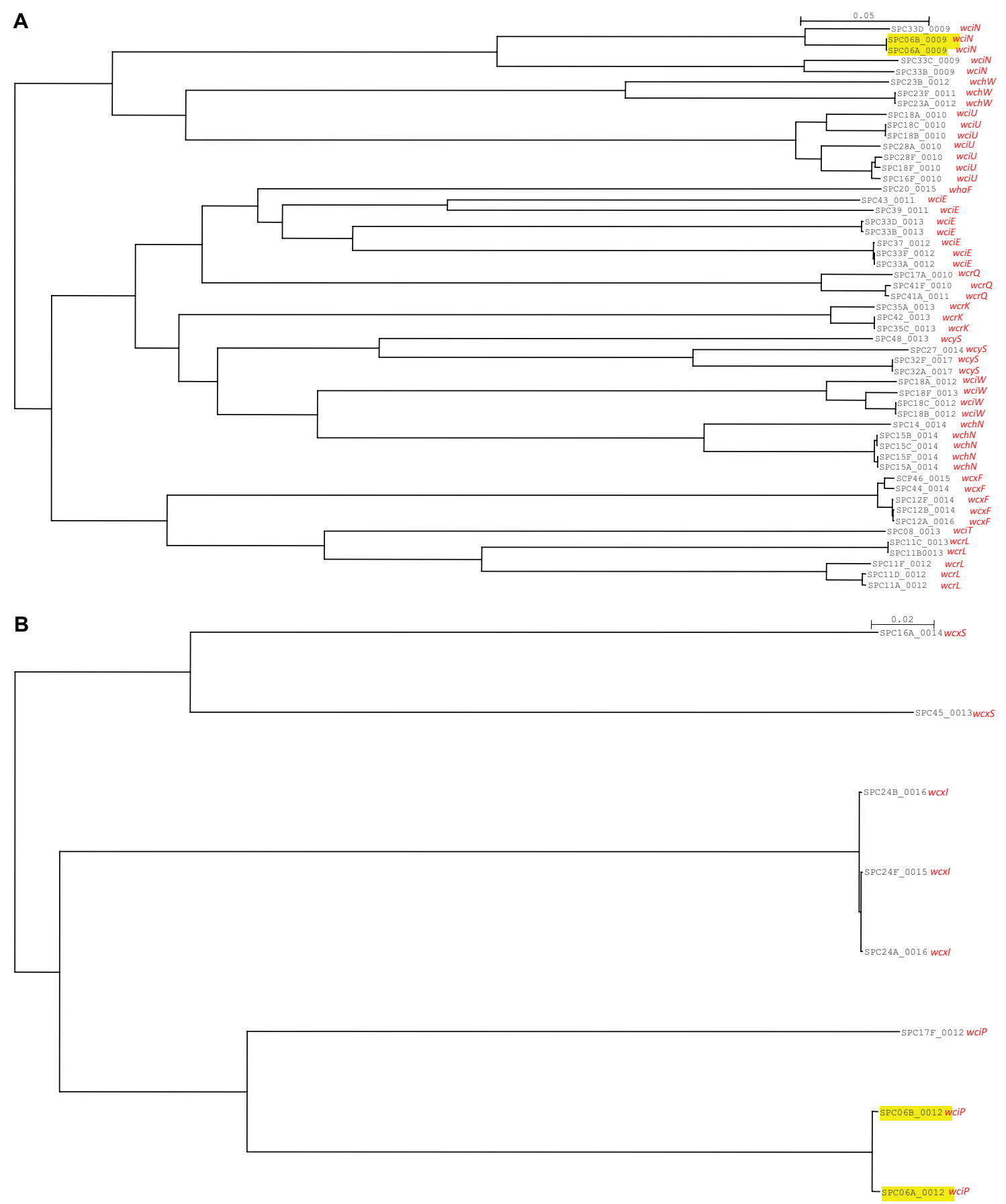

Figure 2 Partial view of the glycosyltransferase (GT) phylogenetic tree. The sequence names are given as SPC-serotype-Sanger Institute database gene number. The GT gene name given by the Sanger Institute is shown in red.

were separated into 64 phylogenetic groups (Table 3). For example, strains belonging to serogroup 19 were divided into 4 groups (serotype 19F, 19A, 19B, and 19C) since these groups had different GT gene number and the sequences were distinguishable. On the other hand, strains belonging to serogroup 6 (serotype 6A and 6B) had very similar GT genes, so that they were indistinguishable and put into same group.

\section{Sequencing GT genes of clinical isolates and phylogenetic analysis}

Because the Sanger Institute used a single strain for each serotype when sequencing the cps locus, we assessed sequence conservation among the GT gene of several representative strains of two serogroups. Six clinical isolates were selected from serogroup 6 and seven from serotype 19F by antiserum testing. The $w c i P$ of serogroup 6 and $w c h Q$ of serotype $19 \mathrm{~F}$ 
Table 3 Grouping of 90 serotypes into 64 groups using glycosyltransferase gene sequence polymorphisms

\begin{tabular}{|c|c|c|c|c|}
\hline I & $10 \mathrm{C}$ & $18 B / 18 C$ & $16 \mathrm{~F} / 28 \mathrm{~F} / 28 \mathrm{~A}$ & $4 \mathrm{IF}$ \\
\hline 2 & IIF & $19 \mathrm{~F}$ & 31 & $4 I A$ \\
\hline 3 & IIA/IID & 19A & $32 \mathrm{~F} / 32 \mathrm{~A}$ & 42 \\
\hline 4 & $I|B / I| C$ & 19B & $33 \mathrm{~F} / 33 \mathrm{~A} / 37$ & 43 \\
\hline 5 & $\mid 2 \mathrm{~F} / \mathrm{|} 2 \mathrm{~A} / \mathrm{I} 2 \mathrm{~B} / 44 / 46$ & $19 \mathrm{C}$ & $33 B$ & 45 \\
\hline $6 \mathrm{~A} / 6 \mathrm{~B}$ & 13 & 20 & $33 \mathrm{C}$ & $47 \mathrm{~F}$ \\
\hline $7 F / 7 A$ & 14 & 21 & $33 \mathrm{D}$ & $47 \mathrm{~A}$ \\
\hline $7 \mathrm{~B} / 7 \mathrm{C} / 40$ & $15 F / I 5 A$ & $22 F / 22 A$ & 34 & 48 \\
\hline 8 & $15 B / 15 C$ & $23 \mathrm{~F} / 23 \mathrm{~A}$ & $35 \mathrm{~F}$ & \\
\hline $9 A / 9 V$ & $16 \mathrm{~A}$ & $23 \mathrm{~B}$ & $35 \mathrm{~A} / 35 \mathrm{C}$ & \\
\hline $9 L / 9 N$ & $17 \mathrm{~F}$ & $24 F / 24 A / 24 B$ & $35 B$ & \\
\hline $\mathrm{IOF}$ & I7A & $25 \mathrm{~F} / 25 \mathrm{~A}$ & 36 & \\
\hline IOA & $18 \mathrm{~F}$ & 27 & 38 & \\
\hline IOB & $18 \mathrm{~A}$ & 29 & 39 & \\
\hline
\end{tabular}

were sequenced. All of the $w c i P$ sequences from clinical samples were similar to those taken from the Sanger database (Figure 3A). Likewise, the $w c h Q$ sequences perfectly matched the web data for serotype 19F (Figure 3B).

\section{Discussion}

Several molecular capsular-typing methods of S. pneumoniae have been developed based on serotype-specific sequences. ${ }^{17-26}$ In this study, we focused on the GT genes due to their role in forming capsular polysaccharides. Each serotype contains
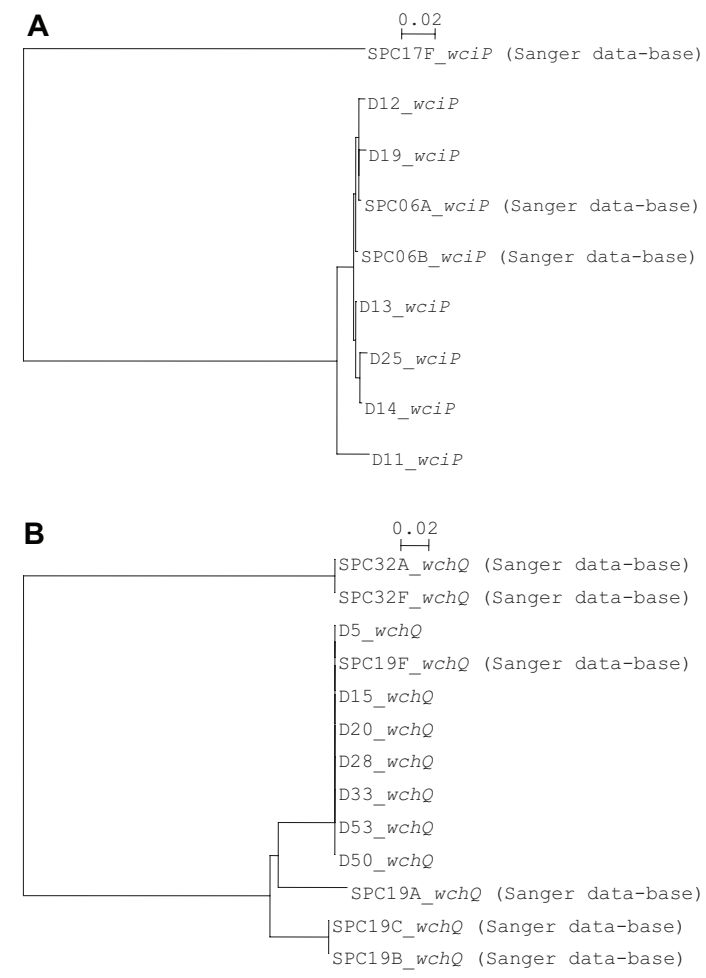

Figure 3 Phylogenetic trees of glycosyltransferase gene sequences using web data and clinical isolates. A) Phylogenetic tree of wciP. B) Phylogenetic tree of wchQ. various sets of GT genes in the cps locus. A phylogenetic tree based on nucleotide sequences was made to explore the sequence diversity and relatedness of the GT genes in each $c p s$ locus (Figure 1). The structure of the tree showed that 90 serotypes used for this study could be divided into 64 phylogenetic groups on the basis of GT gene sequence, and that these sequences can be used to differentiate serotype. The management of pneumococcal disease has become more difficult because of the rapid increase of antimicrobial resistance. It is generally agreed that the use of an effective pneumococcal vaccine during infancy could significantly reduce the morbidity and mortality associated with pneumococcal infections among young children. A 7-valent anti-pneumococcal vaccine is already licensed in several countries and has shown promising results. ${ }^{27-30}$ Thus, clinical monitoring of the disease preventive effects of the anti-pneumococcal vaccine, is increasingly important. In particular, surveillance of the emergence of new capsular types following vaccination aids the development of new vaccines. Our bioinformatic approach will help survey the emergence of new S. pneumoniae capsular types. Sequencing the GT genes of a clinical sample and placing that data into our phylogenetic tree will reveal if this sample has any of the known GT genes of a particular serogroup or serotype. If GT gene sequence differs from that of known GT genes, the sample could contain an emergent $S$. pneumoniae CPS.

The clinical samples that were classified as serogroup 6 also grouped with the serogroup 6 in the Sanger Institute database. However, serological assays further divide serogroup 6 into serotype 6A, 6B, and 6C..$^{31}$ The cps loci of serotypes $6 \mathrm{~A}$ and $6 \mathrm{~B}$ are almost identical, except for a single nucleotide polymorphism in wciP. ${ }^{32}$ Serotype 6C appears to have originated from a single recombination event in which the $6 \mathrm{~A} w c i N$ gene was replaced by a different $w c i N$ gene of unknown origin. ${ }^{33}$ These results indicate that sequencing the GT genes of clinical isolates of $S$. pneumoniae and knowing the differences in these sequences by phylogenetic analysis will help to identify new capsular type of $S$. pneumoniae.

\section{Acknowledgment}

This study was performed using special coordination funds for promoting science and technology for the Ministry of Education, Culture, Sports, Science and Technology, Japan.

\section{Disclosure}

The authors declared no conflicts of interest in relation to this paper. 


\section{References}

1. Zangwill KM, Vadheim CM, Vannier AM, Hemenway LS, Greenberg DP, Ward JI. Epidemiology of invasive pneumococcal disease in southern California: implications for the design and conduct of a pneumococcal conjugate vaccine efficacy trial. J Infect Dis. 1996;174(4):752-759.

2. Henrichsen J. Six newly recognized types of Streptococcus pneumoniae. J Clin Microbiol. 1995;33(10):2759-2762.

3. Trollfors B, Burman L, Dannetun E, Llompart J, Norrby R. Serotyping of Streptococcus pneumoniae strains by coagglutination and counterimmunoelectrophoresis. J Clin Microbiol. 1983;18(4):978-980.

4. Farrell DJ, Jenkins SG, Reinert RR. Global distribution of Streptococcus pneumoniae serotypes isolated from paediatric patients during 1999-2000 and the in vitro efficacy of telithromycin and comparators. J Med Microbiol. 2004;53(Pt 11):1109-1117.

5. Bridy-Pappas AE, Margolis MB, Center KJ, Isaacman DJ. Streptococcus pneumoniae: description of the pathogen, disease epidemiology, treatment, and prevention. Pharmacotherapy. 2005;25(9):1193-1212.

6. Hausdorff WP, Feikin DR, Klugman KP. Epidemiological differences among pneumococcal serotypes. Lancet Infect Dis. 2005;5:83-93.

7. Henrichsen J. Typing of Streptococcus pneumoniae: past, present and future. Am J Med. 1999;107(1A):505-508.

8. Lalitha MK, Pai R, John TJ, et al. Serotyping of Streptococcus pneumoniae by agglutination assays: a cost-effective technique for developing countries. Bull WHO. 1996;74(4):387-390.

9. Singhal A, Lalitha MK, John TJ, et al. Modified Latex agglutination test for rapid detection of Streptococcus pneumoniae and Haemophilus influenzae in cerebrospinal fluid and direct serotyping of Streptococcus pneumoniae. Eur J Clin Microbiol Infect Dis. 1996;15:472-477.

10. Heidelberger M. Precipitating cross-reactions among pneumococcal types. Infect Immun. 1983;41:1234-1244.

11. Kumar A, Mariappuram J, Kim CH. Discrepancies in fluorescent antibody, counterimmunoelectrophoresis, and Neufeld test for typing of Streptococcus pneumoniae. Diagn Microbiol Infect Dis. 1985;3: 509-514.

12. Bentley SD, Aanensen DM, Mavroidi A, et al. Genetic analysis of the capsular biosynthetic locus from all 90 pneumococcal serotypes. PLoS Genetics. 2006;2:e31.

13. Llull D, Lopez R, Garcia E. Genetic bases and medical relevance of capsular polysaccharide biosynthesis in pathogenic streptococci. Curr Mol Med. 2001;1:475-491.

14. Aanensen DM, Mavroidi A, Bentley SD, Reeves PR, Spratt BG. Predicted functions and linkage specificities of the products of the Streptococcus pneumoniae capsular biosynthetic loci. J Bacteriol. 2007; 189:7856-7876.

15. Thompson JD, Gibson TJ, Plewniak F, Jeanmougin F, Higgins DG. The CLUSTAL_X windows interface: flexible strategies for multiple sequence alignment aided by quality analysis tools. Nucleic Acids Res. 1997;25:4876-4882.

16. Perriere G, Gouy M. WWW-query: an on-line retrieval system for biological sequence banks. Biochimie. 1996;78:364-369.

17. Brito DA, Ramirez M, de Lencastre H. Serotyping Streptococcus pneumoniae by multiplex PCR. J Clin Microbiol. 2003;41:2378-2384.
18. Kong F, Brown M, Sabananthan A, Zeng X, Gilbert GL. Multiplex PCR-based reverse line blot hybridization assay to identify 23 Streptococcus pneumoniae polysaccharide vaccine serotypes. J Clin Microbiol. 2006;44:1887-1891.

19. Kong F, Gilbert GL. Using cpsA-cpsB sequence polymorphisms and serotype-/group-specific PCR to predict 51 Streptococcus pneumoniae capsular serotypes. J Med Microbiol. 2003;52:1047-1058.

20. Kong F, Wang W, Tao J, et al. A molecular-capsular-type prediction system for 90 Streptococcus pneumoniae serotypes using partial cpsAcps $B$ sequencing and wzy- or wzx-specific PCR. J Med Microbiol. 2005;54:351-356.

21. Lawrence ER, Arias CA, Duke B, et al. Evaluation of serotype prediction by cpsA-cpsB gene polymorphism in Streptococcus pneumoniae. J Clin Microbiol. 2000;38:1319-1323.

22. Lawrence ER, Griffiths DB, Martin SA, George RC, Hall LM. Evaluation of semiautomated multiplex PCR assay for determination of Streptococcus pneumoniae serotypes and serogroups. J Clin Microbiol. 2003;41:601-607.

23. Pai R, Gertz RE, Beall B. Sequential multiplex PCR approach for determining capsular serotypes of Streptococcus pneumoniae isolates. J Clin Microbiol. 2006;44:124-131.

24. Zhou F, Kong F, Tong Z, Gilbert GL. Identification of less-common Streptococcus pneumoniae serotypes by a multiplex PCR-based reverse line blot hybridization assay. J Clin Microbiol. 2007;45:3411-3415.

25. Batt SL, Charalambous BM, McHugh TD, Martin S, Gillespie SH. Novel PCR-restriction fragment length polymorphism method for determining serotypes or serogroups of Streptococcus pneumoniae isolates. J Clin Microbiol. 2005;43:2656-2661.

26. Wang Q, Wang M, Kong F, et al. Development of a DNA microarray to identify the Streptococcus pneumoniae serotypes contained in the 23 -valent pneumococcal polysaccharide vaccine and closely related serotypes. J Microbiol Methods. 2007;68:128-136.

27. Kyaw MH, Lynfield R, Schaffner W, et al. Effect of introduction of the pneumococcal conjugate vaccine on drug-resistant Streptococcus pneumoniae. N Engl J Med. 2006;354:1455-1463.

28. Poehling KA, Talbot TR, Griffin MR, et al. Invasive pneumococcal disease among infants before and after introduction of pneumococcal conjugate vaccine. JAMA. 2006;295:1668-1674.

29. Whitney CG, Farley MM, Hadler J, et al. Decline in invasive pneumococcal disease after the introduction of protein-polysaccharide conjugate vaccine. $N$ Engl J Med. 2003;348:1737-1746.

30. Whitney CG, Pilishvili T, Farley MM, et al. Effectiveness of sevenvalent pneumococcal conjugate vaccine against invasive pneumococcal disease: a matched case-control study. Lancet. 2006;368:1495-1502.

31. Park IH, Pritchard DG, Cartee R, Brandao A, Brandileone MCC, Nahm MH. Discovery of a new capsular serotype (6C) within serogroup 6 of Streptococcus pneumoniae. J Clin Microbiol. 2007;45:1225-1233.

32. Mavroidi A, Godoy D, Aanensen DM, Robinson DA, Hollingshead SK, Spratt BG. Evolutionary genetics of the capsular locus of serogroup 6 pneumococci. J Bacteriol. 2004;186:8181-8192.

33. Park IH, Park S, Hollingshead SK, Nahm MH. Genetic basis for the new pneumococcal serotype, 6C. Infect Immun. 2007;75:4482-4489.

Open Access Bioinformatics

\section{Publish your work in this journal}

Open Access Bioinformatics is an international, peer-reviewed, open access journal publishing original research, reports, reviews and commentaries on all areas of bioinformatics. The manuscript management system is completely online and includes a very quick and fair

peer-review system. Visit http://www.dovepress.com/testimonials.php to read real quotes from published authors. 